\title{
Factors Associated with Quit Interest and Quit Attempts among Young Adult JUUL Users
}

\author{
Mahmood A. Alalwan ${ }^{1, * \mathbb{D}}$, Jill M. Singer ${ }^{2}$ and Megan E. Roberts ${ }^{2}$ \\ 1 Division of Epidemiology, College of Public Health, The Ohio State University, Columbus, OH 43210, USA \\ 2 Division of Health Behavior and Health Promotion, College of Public Health, The Ohio State University, \\ Columbus, OH 43210, USA; singer.159@osu.edu (J.M.S.); Roberts.1558@osu.edu (M.E.R.) \\ * Correspondence: alalwan.2@osu.edu
}

check for updates

Citation: Alalwan, M.A.; Singer, J.M.; Roberts, M.E. Factors Associated with Quit Interest and Quit Attempts among Young Adult JUUL Users. Int. J. Environ. Res. Public Health 2022, 19, 1403. https://doi.org/10.3390/ ijerph19031403

Academic Editor: Vaughan W. Rees

Received: 14 January 2022

Accepted: 24 January 2022

Published: 27 January 2022

Publisher's Note: MDPI stays neutral with regard to jurisdictional claims in published maps and institutional affiliations.

Copyright: (C) 2022 by the authors. Licensee MDPI, Basel, Switzerland. This article is an open access article distributed under the terms and conditions of the Creative Commons Attribution (CC BY) license (https:// creativecommons.org/licenses/by/ $4.0 /)$.

\begin{abstract}
Despite reports suggesting young people are interested in quitting e-cigarettes, little work has examined predictors of quit outcomes. This study aimed to identify factors associated with quit outcomes among JUUL e-cigarette users in a longitudinal sample of young adults. We assessed undergraduate past-30-day JUUL users during autumn 2018 ( $N=225)$; Our outcomes included shortterm quit attempts and interest (spring 2019), and long-term quit attempts (spring 2020). We used logistic regression to examine the associations between our outcomes and JUUL use characteristics, other tobacco use, and sociodemographic factors. Findings indicated $76 \%$ of users were interested in quitting JUUL, and more than $40 \%$ reported a quit attempt. Quit outcomes were not related to sociodemographics. Short-term quit outcomes were more likely among freshmen and less likely among recent cigarillo users. Heavy JUUL users were more likely to report short- and long-term quit attempts, but JUUL device owners were less likely to report short- and long-term quit attempts. Higher nicotine dependence reduced the likelihood of a long-term quit attempt. There is a need for policy level actions that address tobacco control among this population. Findings suggest a range of unique factors that can inform such policies and programs to curb young adult e-cigarette use.
\end{abstract}

Keywords: e-cigarette; JUUL; young adult; quit attempt; quit interest; cessation

\section{Introduction}

In the United States, e-cigarette use has increased dramatically over the last few years, particularly among young people. Nationally, past 30-day (current) e-cigarette use surged from $1.5 \%$ in 2011 to $19.6 \%$ in 2020 among high school students and was their most widely used tobacco product [1,2]. Similarly, young adults showed widespread use of e-cigarettes. A recent national survey estimated the prevalence of current e-cigarette use among young adults aged 18-24 years at 7.6\%, the highest prevalence compared to all other adult age groups, including middle-aged and older adults [3].

The high prevalence of e-cigarette use was likely precipitated by JUUL, an e-cigarette brand that revolutionized the market with a high-tech design resembling a USB flash drive. In a relatively short period, JUUL comprised over $70 \%$ of the e-cigarette market share [4]. The popularity of this particular brand seems to be particularly high among young people, with an estimated prevalence of 13\% among 18-20 years old and 8.2\% among 21-24 years old [4-8]. This may be partly due to the nicotine salt used in JUUL's e-liquids, which allows for higher nicotine delivery with less irritation and better sensory experience compared to older e-cigarettes and e-liquids that used free-base nicotine [9], prompting speculations of its high abuse liability.

Despite the high prevalence, popularity, and potential abuse liability of JUUL, research surrounding JUUL cessation (or any e-cigarette cessation) is still developing. A few reports and anecdotal evidence indicate a desire among JUUL users to quit [10-16]. For example, cross-sectional studies showed nearly half or more of young adult e-cigarette users reported 
a quit attempt $[13,15]$. A few studies have also identified barriers or facilitators to ecigarette cessation, including nicotine dependence, stress, expectancies for e-cigarette use, perceived health risks, social pressure, and environmental factors such as expense, availability, and social acceptability [13-16]. Additionally, qualitative evidence suggests that e-cigarette cessation interventions should consider motivation strategies, social pressure, and withdrawal symptoms [12]. Nevertheless, very little work has examined quit outcomes related to JUUL, including quit interest and quit attempts [13]. The aim of the present study was to identify factors associated with quit interest and quit attempts among JUUL users in a longitudinal sample of young adults.

\section{Materials and Methods}

\subsection{Participants and Recruitment}

Our data were from a cohort study examining tobacco use among undergraduates at a large Midwestern University. Before the start of the 2016 autumn semester, our research team contacted 1000 incoming freshmen, who were a random sample of the incoming first-year students aged 18 or older, stratified by first-generation college status, gender, and in- versus out-of-state family residence. An email with a link to an online survey was sent to these students, inviting them to participate in a research study on health behaviors, which yielded 529 respondents. We re-contacted these students in their third year, before the autumn semester in 2018. Simultaneously, we contacted a new random sample of 1000 freshmen, which were recruited in the same way as described above, which yielded 611 new freshmen respondents. The University's Institutional Review Board approved all study methods. Surveys were sent to both cohorts in August, September, and December 2018 (autumn), as well as March and June (spring) 2019. A final follow-up survey was sent in March 2020. Our study population of current JUUL users included those who reported past-30-day JUUL use at any timepoint in autumn 2018 and who completed at least one survey during spring 2019.

\subsection{Procedures}

At enrollment (2016 or 2018), participants completed an online consent form, followed by a 15-min survey. The initial survey contained questions related to the participants' ever and past 30-day use of various tobacco products, including e-cigarettes. To address the national surge in JUUL use that occurred in 2018, we added new questions to assess JUUL use specifically during the 2018-2019 academic year.

\subsection{Variables}

\subsubsection{Outcomes}

The main outcomes of interest in this analysis were short- and long term quit attempts, and short-term quit interest.

Short- and long-term quit attempt status were defined as any reported attempt to quit JUUL during spring 2019 and spring 2020, respectively. At both time points, participants were asked "What best describes your current intentions regarding quitting JUUL?" Participants who selected response options of "currently undergoing a quit attempt", or "I have already quit", and who also reported no JUUL use in the past 30 days, were coded as making a quit attempt.

Short-term quit interest status was defined as any reported interest in quitting JUUL during spring 2019. Participants were asked "Have you ever seriously considered quitting JUUL?" Response options were "yes" (coded as having an interest in quitting) and "no" (coded as no interest in quitting). Participants undergoing a quit attempt were excluded from coding for this variable.

\subsubsection{Factors Associated with Short-Term Outcomes}

Factors expected to be associated with short-term quit attempt and quit interest were all measured in autumn 2018. Factors related to characteristics of JUUL use included 
owning a JUUL device, heaviness of use, JUUL use frequency, and having friends who use JUUL. Heaviness of use was assessed with the question "Think about your JUUL use over the past 30 days. If you were using a JUUL by yourself without sharing, how long would it take you to finish one pod?" Responses were dichotomized as "less than 1 month" versus " 1 month or more". JUUL use frequency was assessed with the question "In the past 30 days, on how many days did you use JUUL?" Responses were dichotomized as "10 days or less" versus "more than 10 days". Friends who use JUUL was coded into three levels: "none-a few", "some", or "most-all". When questions were asked on more than one autumn survey, the most recent participant response was used.

Factors related to other tobacco use included any past-30-day use reported during autumn for cigarettes (yes/no), cigars (yes/no), cigarillos (yes/no), hookah (yes/no), and smokeless tobacco (yes/no).

Risk perceptions of JUUL use were assessed using two questions. For the first, we asked "Compared to one pack of cigarettes, how much nicotine do you think is in one JUUL pod?" with the following response options: "there is more nicotine in the cigarette pack", "there is more nicotine in the JUUL pod", or "they are about the same". For the second, we asked "Compared to one pack of cigarettes, how dangerous is it to vape one JUUL pod?" with the following response options: "cigarettes are more dangerous", "JUULs are more dangerous", or "they are about the same". The most recent responses in autumn were used.

\subsubsection{Factors Associated with Long-Term Outcomes}

To predict long-term quit attempt, we used factors related to characteristics of JUUL use, other tobacco use, and risk perceptions of JUUL use measured in autumn 2019, using the same definitions as described above. We also included JUUL flavor, which was defined as "mint", "fruit", and "other flavors". Additionally, we included scores from the Hooked on Nicotine Checklist (HONC), the Wisconsin Smoking Withdrawal Scale (WSWS), and the E-cigarette Dependence Scale (EDS), measured in autumn 2019 as continuous variables.

\subsubsection{Sociodemographic Factors}

Social and demographic factors were used to predict short-term quit attempt, shortterm quit interest, and long-term quit attempt. These factors included gender, race/ethnicity, and socioeconomic status (SES), which were measured when participants completed their baseline survey. Students' cohort was defined as "freshmen" or "juniors" based on their year in autumn 2018. We measured SES in terms of three indicators: social class growing up, current social class [17], and parent education (separately assessed for each parent). Our measure of SES was created by calculating and aggregating a z-score for each of these four indicators.

\subsection{Statistical Analysis}

To describe our sample, we presented the characteristics of our study sample using counts and percentages. We also used Chi square tests for categorical variables and two-sample $t$-tests/Wilcoxon Rank Sum tests for continuous variables to describe the associations of each factor of interest with the quit outcomes.

We used separate logistic regression models for each outcome of interest. In general, we used 10 outcome events per predictor variable in our models. To build our models, we used purposeful selection to identify significant factors $[18,19]$. Specifically, we started with univariable logistic regression analyses for each predictor, with significance defined at $p<0.20$, followed by a multivariable model with all significant factors. A variable was kept in the multivariable model at $p<0.05$ or if its removal induced a coefficient estimate change $>20 \%$ in other variables. Next, we added back the variables excluded from the univariable analyses to the multivariable model, one at a time, and each was assessed for statistical significance at $p<0.05$. Due to the low sample size and to correct for potential overfitting, we used a bootstrap estimator to calculate confidence intervals [20]. Finally, we checked 
model assumptions and assessed for potential interactions. All analyses were conducted using SAS 9.4 (Cary, NC, USA).

\section{Results}

\subsection{Descriptive Statistics}

Our final analytical sample included 225 current JUUL users. Of those, $83 \%$ were white, 58\% female, and 60\% freshmen. Nearly all $(213,95 \%)$ respondents reported their short-term quit attempt status (spring 19), 139 (62\%) reported their short-term quit interest (spring 19), and $163(72 \%)$ reported their long-term quit attempt status (spring 20). There were no differences in race/ethnicity $(p=0.89)$, gender $(p=0.38)$, or SES scores $(p=0.50)$ between the two cohorts. Tables 1 and 2 show the descriptive characteristics of our sample by short- and long-term outcomes.

About $43 \%$ of JUUL users reported a short-term quit attempt. Race/ethnicity $(p=0.61)$ gender $(p=0.14)$, and cohort $(p=0.07)$ did not differ by short-term quit attempt status. Approximately $8 \%$ of those who made a short-term quit attempt had recently used cigarillos, compared to $21 \%$ of those who did not make an attempt $(p<0.01)$. Additionally, about $4 \%$ had recently used cigarettes and $2 \%$ had recently used smokeless tobacco among those who made a short-term quit attempt, compared to $21 \%(p<0.01)$ and $11 \%(p=0.02)$ of those who did not make an attempt, respectively. Of those who made a short-term quit attempt, $12 \%$ owned a JUUL device and $78 \%$ took a month or more to finish a JUUL pod, compared to $37 \%$ and $32 \%(p<0.01)$ among those who did not make an attempt, respectively. Over $31 \%$ of those making a short-term quit attempt indicated there was more nicotine in JUUL than cigarettes, compared to $20 \%$ among those who did not make an attempt $(p=0.09)$. The mean SES scores were similar for those who made and did not make a short-term quit attempt $(p=0.73)$.

Table 1. Descriptive characteristics of current JUUL users by short-term quit outcomes.

\begin{tabular}{|c|c|c|c|c|c|c|c|c|c|c|}
\hline & \multicolumn{4}{|c|}{ Short-Term Quit Attempt $(N=213)$} & \multicolumn{6}{|c|}{ Short-Term Quit Interest $(N=139)$} \\
\hline & \multicolumn{2}{|c|}{ No } & \multicolumn{2}{|c|}{ Yes } & \multirow[b]{2}{*}{$p$ Value $^{+}$} & \multicolumn{2}{|c|}{ No } & \multicolumn{2}{|c|}{ Yes } & \multirow[b]{2}{*}{$p$ Value $^{\dagger}$} \\
\hline & $n$ & $\%$ & $n$ & $\%$ & & $n$ & $\%$ & $n$ & $\%$ & \\
\hline \multicolumn{11}{|c|}{ Race Ethnicity } \\
\hline White & 105 & 86.1 & 76 & 83.5 & 0.607 & 26 & 76.5 & 92 & 87.6 & 0.115 \\
\hline Other & 17 & 13.9 & 15 & 16.5 & & 8 & 23.5 & 13 & 12.4 & \\
\hline \multicolumn{11}{|l|}{ Gender } \\
\hline Female & 65 & 53.3 & 57 & 63.3 & 0.143 & 16 & 47.1 & 59 & 56.7 & 0.326 \\
\hline Male & 57 & 46.7 & 33 & 36.7 & & 18 & 52.9 & 45 & 43.3 & \\
\hline Missing & & & 1 & & & & & 1 & & \\
\hline \multicolumn{11}{|l|}{ Cohort } \\
\hline Juniors & 55 & 45.1 & 30 & 33.0 & 0.074 & 18 & 52.9 & 37 & 35.2 & 0.067 \\
\hline Freshmen & 67 & 54.9 & 61 & 67.0 & & 16 & 47.1 & 68 & 64.8 & \\
\hline \multicolumn{11}{|c|}{$\begin{array}{l}\text { Autumn } 18 \text { Recent } \\
\text { Cigarette Use }\end{array}$} \\
\hline No & 97 & 79.5 & 87 & 95.6 & 0.001 & 29 & 85.3 & 84 & 80.0 & 0.491 \\
\hline Yes & 25 & 20.5 & 4 & 4.4 & & 5 & 14.7 & 21 & 20.0 & \\
\hline \multicolumn{11}{|c|}{$\begin{array}{c}\text { Autumn } 18 \text { Recent } \\
\text { Cigar Use }\end{array}$} \\
\hline No & 101 & 82.8 & 79 & 86.8 & 0.422 & 31 & 91.2 & 85 & 81.0 & 0.163 \\
\hline Yes & 21 & 17.2 & 12 & 13.2 & & 3 & 8.8 & 20 & 19.1 & \\
\hline
\end{tabular}


Table 1. Cont.

\begin{tabular}{|c|c|c|c|c|c|c|c|c|c|c|}
\hline & \multicolumn{4}{|c|}{ Short-Term Quit Attempt $(N=213)$} & \multicolumn{6}{|c|}{ Short-Term Quit Interest $(N=139)$} \\
\hline & \multicolumn{2}{|c|}{ No } & \multicolumn{2}{|c|}{ Yes } & \multirow[b]{2}{*}{$p$ Value $^{+}$} & \multicolumn{2}{|c|}{ No } & \multicolumn{2}{|c|}{ Yes } & \multirow[b]{2}{*}{$p$ Value } \\
\hline & $n$ & $\%$ & $n$ & $\%$ & & $n$ & $\%$ & $n$ & $\%$ & \\
\hline \multicolumn{11}{|l|}{$\begin{array}{l}\text { Autumn } 18 \text { Recent } \\
\text { Cigarillo Use }\end{array}$} \\
\hline No & 96 & 78.7 & 84 & 92.3 & 0.007 & 22 & 64.7 & 89 & 84.8 & 0.011 \\
\hline Yes & 26 & 21.3 & 7 & 7.7 & & 12 & 35.3 & 16 & 15.2 & \\
\hline \multicolumn{11}{|l|}{$\begin{array}{c}\text { Autumn } 18 \text { Recent } \\
\text { Hookah Use }\end{array}$} \\
\hline No & 109 & 89.3 & 85 & 93.4 & 0.304 & 31 & 91.2 & 94 & 89.5 & 0.781 \\
\hline Yes & 13 & 10.7 & 6 & 6.6 & & 3 & 8.8 & 11 & 10.5 & \\
\hline \multicolumn{11}{|l|}{$\begin{array}{c}\text { Autumn } 18 \text { Recent } \\
\text { Smokeless Tobacco Use }\end{array}$} \\
\hline No & 109 & 89.3 & 89 & 97.8 & 0.017 & 32 & 94.1 & 94 & 89.5 & 0.424 \\
\hline Yes & 13 & 10.7 & 2 & 2.2 & & 2 & 5.9 & 11 & 10.5 & \\
\hline \multicolumn{11}{|l|}{ Owning JUUL Device } \\
\hline No & 77 & 63.1 & 80 & 87.9 & $<0.001$ & 24 & 70.6 & 70 & 66.7 & 0.671 \\
\hline Yes & 45 & 36.9 & 11 & 12.1 & & 10 & 29.4 & 35 & 33.3 & \\
\hline \multicolumn{11}{|l|}{ Heaviness of Use } \\
\hline Pod Finished in $<1$ month & 73 & 67.6 & 18 & 22.5 & $<0.001$ & 18 & 60.0 & 61 & 64.9 & 0.627 \\
\hline $\begin{array}{l}\text { Pod Finished in } \\
\geq 1 \text { month }\end{array}$ & 35 & 32.4 & 62 & 77.5 & & 12 & 40.0 & 33 & 35.1 & \\
\hline Missing & 14 & & 11 & & & 4 & & 11 & & \\
\hline \multicolumn{11}{|l|}{ Friends who use JUUL } \\
\hline None-A few & 16 & 13.1 & 27 & 29.7 & 0.008 & 6 & 17.7 & 16 & 15.2 & 0.396 \\
\hline Some & 60 & 49.2 & 41 & 45.1 & & 13 & 38.2 & 54 & 51.4 & \\
\hline Most-All & 46 & 37.7 & 23 & 25.3 & & 15 & 44.1 & 35 & 33.3 & \\
\hline \multicolumn{11}{|l|}{$\begin{array}{l}\text { Nicotine in JUUL } \\
\text { compared to } \\
\text { Cigarette Pack }\end{array}$} \\
\hline The same & 77 & 65.8 & 46 & 51.1 & 0.087 & 21 & 61.8 & 66 & 66.0 & 0.848 \\
\hline More in cigarette pack & 17 & 14.5 & 16 & 17.8 & & 5 & 14.7 & 15 & 15.0 & \\
\hline More in JUUL pod & 23 & 19.7 & 28 & 31.1 & & 8 & 23.5 & 19 & 19.0 & \\
\hline Missing & 5 & & 1 & & & & & 5 & & \\
\hline \multicolumn{11}{|l|}{$\begin{array}{c}\text { How Dangerous to Vape } \\
1 \text { JUUL Pod }\end{array}$} \\
\hline The same & 38 & 32.5 & 26 & 28.9 & 0.674 & 9 & 26.5 & 33 & 31.4 & 0.775 \\
\hline $\begin{array}{l}\text { Cigarette is more } \\
\text { dangerous }\end{array}$ & 73 & 62.4 & 57 & 63.3 & & 23 & 67.7 & 62 & 59.1 & \\
\hline JUUL is more dangerous & 6 & 5.1 & 7 & 7.8 & & 2 & 5.9 & 5 & 4.8 & \\
\hline \multirow[t]{2}{*}{ Missing } & 5 & & 1 & & & & & 5 & 4.8 & \\
\hline & Mean & SD & Mean & SD & & Mean & SD & Mean & SD & \\
\hline Socioeconomic Status & 0.11 & 0.69 & 0.08 & 0.71 & 0.732 & 0.10 & 0.64 & 0.10 & 0.71 & 0.947 \\
\hline
\end{tabular}

$+p$ value for $\mathrm{Chi}^{2}$ test for categorical variables. Two-sample $t$-test/Wilcoxon Rank Sum test was used for continuous variables. 
Table 2. Descriptive Characteristics of Current JUUL users by Long-Term Quit Attempt.

\begin{tabular}{|c|c|c|c|c|c|}
\hline & \multicolumn{4}{|c|}{ Long-Term Quit Attempt $(N=163)$} & \multirow[b]{3}{*}{$p$ Value $^{\dagger}$} \\
\hline & \multicolumn{2}{|c|}{ No } & \multicolumn{2}{|c|}{ Yes } & \\
\hline & $n$ & $\%$ & $n$ & $\%$ & \\
\hline \multicolumn{6}{|l|}{ Race Ethnicity } \\
\hline White & 73 & 88.0 & 67 & 81.7 & 0.263 \\
\hline Other & 10 & 12.0 & 15 & 18.3 & \\
\hline \multicolumn{6}{|l|}{ Gender } \\
\hline Female & 47 & 56.6 & 47 & 57.3 & 0.856 \\
\hline Male & 36 & 43.4 & 34 & 41.5 & \\
\hline Missing & & & 1 & 1.2 & \\
\hline \multicolumn{6}{|l|}{ Cohort } \\
\hline Juniors & 41 & 49.4 & 34 & 41.5 & 0.306 \\
\hline Freshmen & 42 & 50.6 & 48 & 58.5 & \\
\hline \multicolumn{6}{|l|}{ Autumn 18 Recent Cigarette Use } \\
\hline No & 63 & 75.9 & 74 & 90.2 & 0.014 \\
\hline Yes & 20 & 24.1 & 8 & 9.8 & \\
\hline \multicolumn{6}{|l|}{ Autumn 18 Recent Cigar Use } \\
\hline No & 75 & 90.4 & 77 & 93.9 & 0.399 \\
\hline Yes & 8 & 9.6 & 5 & 6.1 & \\
\hline \multicolumn{6}{|l|}{ Autumn 18 Recent Cigarillo Use } \\
\hline No & 72 & 86.7 & 78 & 95.1 & 0.061 \\
\hline Yes & 11 & 13.3 & 4 & 4.9 & \\
\hline \multicolumn{6}{|l|}{ Autumn 18 Recent Hookah Use } \\
\hline No & 77 & 92.8 & 75 & 91.5 & 0.755 \\
\hline Yes & 6 & 7.2 & 7 & 8.5 & \\
\hline \multicolumn{6}{|c|}{ Autumn 18 Recent Smokeless Tobacco Use } \\
\hline No & 75 & 90.4 & 81 & 98.8 & 0.017 \\
\hline Yes & 8 & 9.6 & 1 & 1.2 & \\
\hline \multicolumn{6}{|l|}{ Owning JUUL Device } \\
\hline No & 46 & 56.1 & 69 & 85.2 & $<0.001$ \\
\hline Yes & 36 & 43.9 & 12 & 14.8 & \\
\hline Missing & 1 & & 1 & & \\
\hline \multicolumn{6}{|l|}{ Heaviness of Use } \\
\hline Pod Finished in $<1$ month & 59 & 72.0 & 26 & 32.1 & $<0.001$ \\
\hline Pod Finished in $\geq 1$ month & 23 & 28.0 & 55 & 67.9 & \\
\hline Missing & 1 & & 1 & & \\
\hline \multicolumn{6}{|l|}{ Friends who use JUUL } \\
\hline None-A few & 15 & 18.0 & 19 & 23.2 & 0.267 \\
\hline Some & 36 & 43.4 & 41 & 50.0 & \\
\hline Most-All & 32 & 38.6 & 22 & 26.8 & \\
\hline
\end{tabular}


Table 2. Cont.

\begin{tabular}{|c|c|c|c|c|c|}
\hline & \multicolumn{4}{|c|}{ Long-Term Quit Attempt $(N=163)$} & \multirow[b]{3}{*}{$p$ Value $^{\dagger}$} \\
\hline & \multicolumn{2}{|c|}{ No } & \multicolumn{2}{|c|}{ Yes } & \\
\hline & $n$ & $\%$ & $n$ & $\%$ & \\
\hline \multicolumn{6}{|l|}{ Nicotine in JUUL compared to Cigarette Pack } \\
\hline The same & 46 & 60.5 & 31 & 40.3 & 0.024 \\
\hline More in cigarette pack & 3 & 3.9 & 9 & 11.7 & \\
\hline More in JUUL pod & 27 & 35.5 & 37 & 48.1 & \\
\hline Missing & 7 & & 5 & & \\
\hline \multicolumn{6}{|l|}{ How Dangerous to Vape 1 JUUL Pod } \\
\hline The same & 21 & 27.6 & 28 & 36.4 & 0.298 \\
\hline Cigarette is more dangerous & 47 & 61.8 & 38 & 49.4 & \\
\hline JUUL is more dangerous & 8 & 10.5 & 11 & 14.3 & \\
\hline Missing & 7 & & 5 & & \\
\hline \multicolumn{6}{|l|}{ Flavor Mint } \\
\hline No & 11 & 13.6 & 18 & 22.2 & 0.151 \\
\hline Yes & 70 & 86.4 & 63 & 77.8 & \\
\hline Missing & 2 & & 1 & & \\
\hline \multicolumn{6}{|l|}{ Flavor Fruit } \\
\hline No & 36 & 44.4 & 36 & 44.4 & 1.000 \\
\hline Yes & 45 & 55.6 & 45 & 55.6 & \\
\hline Missing & 2 & & 1 & & \\
\hline \multicolumn{6}{|l|}{ Flavor Other } \\
\hline No & 65 & 80.2 & 62 & 76.5 & 0.567 \\
\hline Yes & 16 & 19.8 & 19 & 23.5 & \\
\hline \multirow[t]{2}{*}{ Missing } & 2 & & 1 & & \\
\hline & Mean & SD & Mean & SD & \\
\hline Hooked on Nicotine Checklist & 2.07 & 3.00 & 0.59 & 1.59 & $<0.001$ \\
\hline Wisconsin Smoking Withdrawal Scale & 1.37 & 0.68 & 0.98 & 0.60 & $<0.001$ \\
\hline E-cigarette Dependence Scale & 2.65 & 3.36 & 0.81 & 1.83 & $<0.001$ \\
\hline Socioeconomic Status & 0.07 & 0.65 & 0.15 & 0.72 & 0.485 \\
\hline
\end{tabular}

$+p$ value for $\mathrm{Chi}^{2}$ test for categorical variables. Two-sample $t$-test/Wilcoxon Rank Sum test was used for continuous variables.

Approximately $76 \%$ of JUUL users were interested in quitting JUUL. Race/ethnicity $(p=0.12)$, gender $(p=0.33)$, and cohort $(p=0.07)$ were similar for those with and without quit interest. Approximately $15 \%$ of those who had quit interest had recently used cigarillos, compared to $35 \%$ of those who were not interested $(p=0.01)$. There was no difference in heaviness of use $(p=0.63)$ and having friends who used JUUL $(p=0.40)$ between those with and without quit interest. Nineteen percent of those with quit interest indicated there was more nicotine in JUUL than cigarettes, compared to $24 \%$ among those who were not interested $(p=0.85)$. The mean SES scores were similar for those with and without quit interest $(p=0.95)$.

About $50 \%$ of those who reported their long-term quit attempt status made a quit attempt. Race/ethnicity $(p=0.26)$, gender $(p=0.86)$, and cohort $(p=0.31)$ did not differ by long-term quit attempt status. Approximately $5 \%$ of those who made a long-term quit attempt had recently used cigarillos, compared to $13 \%$ of those who did not make an 
attempt $(p=0.06)$. Of those who made a long-term quit attempt, 15\% owned a JUUL device and $68 \%$ took a month or more to finish a JUUL pod, compared to $44 \%$ and $28 \%(p<0.01)$ among those who did not make an attempt, respectively. Over $48 \%$ of participants who made a long-term quit attempt indicated there was more nicotine in JUUL than cigarettes, compared to $36 \%$ among those who did not make a quit attempt $(p=0.02)$. Distribution of mint $(p=0.15)$, fruit $(p=1.00)$, and other $(p=0.57)$ flavors were similar among those who made and did not make a long-term quit attempt, with mint being the most common flavor used. The mean scores of HONC $(p<0.01)$, WSWS $(p<0.01)$, and EDS $(p<0.01)$ tended to be lower among those who made a long-term quit attempt, and quitters had higher mean SES scores $(p=0.49)$.

\subsection{Logistic Regressions}

Our multivariable logistic regression analyses showed cohort, heaviness of use, owning a JUUL, and recent cigarillo use were significantly associated with making a short-term quit attempt (Table 3). The odds of a short-term quit attempt for freshmen and those who took a month or more to finish a JUUL pod were $113 \%$ (95\% CI 1.06-4.90) and 500\% (95\% CI 3.14-14.0) higher, compared to juniors and those who took less than a month to finish a JUUL pod, respectively. The odds of a short-term quit attempt for JUUL device owners and recent cigarillo users were 69\% (95\% CI 0.10-0.76) and 75\% (95\% CI 0.05-0.69) lower, compared to those who did not own JUUL devices and non-recent cigarillo users, respectively.

Table 3. Factors associated with short-term quit outcomes among current JUUL users.

\begin{tabular}{|c|c|c|c|c|c|c|c|c|c|c|c|c|}
\hline & \multicolumn{6}{|c|}{ Short-Term Quit Attempt } & \multicolumn{6}{|c|}{ Short-Term Quit Interest } \\
\hline & \multirow[t]{2}{*}{ OR } & \multicolumn{2}{|c|}{$95 \% \mathrm{CI}$} & \multirow[t]{2}{*}{ aOR } & \multicolumn{2}{|c|}{$95 \% \mathrm{CI}$} & \multirow[t]{2}{*}{ OR } & \multicolumn{2}{|c|}{$95 \%$ CI } & \multirow[t]{2}{*}{ aOR } & \multicolumn{2}{|c|}{$95 \% \mathrm{CI}$} \\
\hline & & LCL & UCL & & LCL & UCL & & LCL & UCL & & LCL & UCL \\
\hline \multicolumn{13}{|l|}{ Cohort } \\
\hline Juniors & Ref & & & Ref & & & Ref & & & Ref & & \\
\hline Freshmen & 1.67 & 0.95 & 2.93 & 2.13 & 1.06 & 4.90 & 2.07 & 0.95 & 4.53 & 2.25 & 1.00 & 5.63 \\
\hline \multicolumn{13}{|l|}{ Autumn 18 recent Cigarillo use } \\
\hline No & Ref & & & Ref & & & Ref & & & Ref & & \\
\hline Yes & 0.31 & 0.13 & 0.75 & 0.25 & 0.05 & 0.69 & 0.33 & 0.14 & 0.80 & 0.30 & 0.12 & 0.77 \\
\hline \multicolumn{13}{|l|}{ Heaviness of Use (Autumn 18) } \\
\hline Pod Finished in $<1$ month & Ref & & & Ref & & & & & & & & \\
\hline Pod Finished in $\geq 1$ month & 7.18 & 3.71 & 13.92 & 6.00 & 3.14 & 14.0 & & & & & & \\
\hline \multicolumn{13}{|l|}{ Own JUUL } \\
\hline No & Ref & & & Ref & & & & & & & & \\
\hline Yes & 0.24 & 0.11 & 0.49 & 0.31 & 0.10 & 0.76 & & & & & & \\
\hline
\end{tabular}

OR: Odds Ratio, aOR: adjusted Odds Ratio, CI: Confidence Interval, LCL: Lower Confidence Limit; UCL, Upper Confidence Limit.

Cohort and prior recent cigarillo use were significantly associated with short-term quit interest (Table 3). The odds of short-term quit interest for freshmen were 125\% (95\% CI 1.00-5.63) more likely, compared to juniors. The odds of short-term quit interest for recent cigarillo users were $70 \%$ (95\% CI 0.12-0.77) less likely, compared to non-recent cigarillo users.

Heaviness of JUUL use, owning a JUUL, and WSWS score were significantly associated with long-term quit attempt (Table 4). The odds of long-term quit attempt for participants who took more than a month to finish a JUUL pod were $227 \%$ (95\% CI 1.58-7.48) higher than those who took less than a month to finish a JUUL pod. For JUUL device owners, the odds of a long-term quit attempt were 57\% (95\% CI 0.16-1.07) lower, compared to those 
who did not own a JUUL device. For every 1 unit increase in WSWS score, the odds of long-term quit attempt decreased by $48 \%$ (95\% CI 0.28-0.88).

Table 4. Factors associated with long-term quit attempts among current JUUL users.

\begin{tabular}{|c|c|c|c|c|c|c|}
\hline & \multirow[t]{2}{*}{ OR } & \multicolumn{2}{|c|}{$95 \%$ CI } & \multirow[t]{2}{*}{ aOR } & \multicolumn{2}{|c|}{$95 \% \mathrm{CI}$} \\
\hline & & LCL & UCL & & LCL & UCL \\
\hline \multicolumn{7}{|l|}{ Heaviness of Use (Spring 19) } \\
\hline Pod Finished in $<1$ month & Ref & & & Ref & & \\
\hline Pod Finished in $\geq 1$ month & 5.43 & 2.78 & 10.61 & 3.27 & 1.58 & 7.48 \\
\hline Own JUUL Spring 19 & Ref & & & \multicolumn{3}{|c|}{ Own JUUL Spring 19} \\
\hline Yes & 0.22 & 0.11 & 0.47 & 0.43 & 0.16 & 1.07 \\
\hline WSWS & 0.39 & 0.24 & 0.66 & 0.52 & 0.28 & 0.88 \\
\hline
\end{tabular}

OR: Odds Ratio, aOR: adjusted Odds Ratio, CI: Confidence Interval, LCL: Lower Confidence Limit; UCL, Upper Confidence Limit.

\section{Discussion}

In our longitudinal sample of young adults, over three-quarters (76\%) of JUUL users expressed an interest in quitting JUUL. Moreover, $43 \%$ reported a quit attempt in our short-term outcomes and 50\% reported a quit attempt in our long-term outcomes. These are clear indicators of a desire to quit JUUL among this population.

Our analyses further indicated that short-term quit attempts and quit interest were more likely among freshmen than juniors, and less likely among recent cigarillo users than non-users. JUUL users who took more than a month to finish a JUUL pod were more likely to report short- or long-term quit attempts, compared to those who took less than a month to finish a JUUL pod. Those who owned a JUUL device were less likely to report short- or long-term quit attempts. A higher WSWS score significantly reduced the likelihood of a long-term quit attempt.

To our knowledge, this study is the first to report factors prospectively associated with JUUL quit attempts and quit interest using a longitudinal sample. This study found about half of current JUUL users reported a quit attempt, consistent with previous crosssectional studies [13,15]. Consistent with our findings, Pulvers and colleagues [13] found no associations between JUUL quit attempts and gender, race/ethnicity, or SES, suggesting that quit attempts were widely distributed among the JUUL user population. However, our study found cohort differences were associated with the short-term quit outcomes, which may reflect a shorter length of use and lower nicotine dependence among freshmen. Unlike our study, Pulvers and colleagues [13] found no associations between cohort or other tobacco use with JUUL quit attempt. This could be explained by differences in variables definitions. Specifically, their definition of cohort, which was freshman/sophomore versus junior/senior/fifth year or higher, combined several categories, possibly grouping diverse participants.

\subsection{Implications}

Consistent with recent literature [11,13], our findings show that quit attempts and quit interest among young adult JUUL users are quite common. These findings indicate the need for e-cigarette cessation support for young adults. Our study adds to the literature, a range of unique factors associated with JUUL quit attempts and quit interest among this population. These factors can inform and guide current cessation programs to support JUUL cessation efforts and prevent relapse among young adults, a population characterized by high JUUL use. In particular, cessation programs may promote JUUL quit attempts and quit interest with proper management of cravings and other nicotine withdrawal symptoms. Our findings also suggest that harm perceptions of JUUL may not play an essential role in quitting JUUL among young adults and may be less emphasized. 
Extant literature on cigarette smoking cessation indicates similar factors related to cessation efforts, as found in the present study. For instance, daily smokers [21] and smokers with lower nicotine dependence [22] were more likely to quit smoking, while smokers with higher heaviness of smoking [23] were more likely to relapse during the first month of a quit attempt. The fact that we found a similar pattern of findings for e-cigarettes is important, as it suggests that some elements of cigarette cessation programs may be similarly successful for e-cigarette cessation programs.

Our findings suggest the need for policy level actions that address tobacco control among young adult current JUUL users. Given the desire to quit JUUL use among many undergraduates, colleges and universities should consider offering or expanding cessation treatments at student health centers. In addition, they should review their campus smokefree policies to ensure e-cigarettes are included, offer educational interventions for first-year students at student orientations, and raise awareness of the campus-based resources for students experimenting with e-cigarettes. Experts also recommend broader-level prevention and intervention efforts. For example, at local and state levels, policymakers, in collaboration with colleges and universities, should reduce the e-cigarette retailer density near campuses [24,25]. Additionally, they should consider a tax increase on e-cigarette devices and their refills, which may curb owning a JUUL or other e-cigarette devices or impact the heaviness of use to promote quit attempts and quit interest among this population. Tax and retailer density policies should be implemented with careful evaluation of potential unintended effects, like an increase in other tobacco products use, such as cigarettes [26]. Thus, it is important to carefully consider measures for mitigating such unintended effects, such as increasing the availability and accessibility of tobacco dependence screening and treatment programs by collaborating with local and state tobacco control advocates.

\subsection{Strengths and Limitations}

One of the most important strengths of this study is its longitudinal design, which helps suggest a temporal association between the examined factors and JUUL quit outcomes. Lack of temporal clarity is a major limitation for studies investigating quit related outcomes and e-cigarette use in observational studies. Our study population was drawn from random samples of two cohorts followed prospectively. Assessment of JUUL dependence was wideranging, using the HONC, WSWS, and EDS. Nevertheless, our study had several limitations. Race/ethnicity groups were dichotomized into "white" versus "other race/ethnicity" due to the small number of minority participants. This categorization grouped diverse participants into one category, which may have impacted our ability to make conclusions about JUUL use and cessation-related characteristics across different races/ethnicities. Although our specific measures of quit attempts were adapted from established items in the field of cigarette cessation research, they were not validated for JUUL/e-cigarettes. Moreover, items tested in our models were not theory-informed, but rather based on known risk factors for adolescent/young adult use of other types of tobacco products. Due to the exploratory nature of the study and its small sample size, we did not adjust for multiple comparisons. Larger theory-informed cohort studies are needed to replicate the findings and explore additional constructs (such as quit motivation) among other popular e-cigarette users, especially with the rapidly changing e-cigarette market in the United States. Additionally, this study was limited to one university in one region of the United States, which may limit the generalizability of our findings to other young adults who are not in college, from different regions, or who use other brands of e-cigarettes. Lastly, we did not examine quit outcomes among exclusive e-cigarette users, which may further limit the applicability of our findings to these users.

\section{Conclusions}

JUUL use is prevalent among young adults, but a large proportion of these users have an interest in quitting and are making quit attempts. This emphasizes the high need for tobacco control cessation interventions and policy level actions for this population. The 
present study suggests some unique factors associated with JUUL quit attempts and quit interest that may inform cessation programs and guide policies targeting this population. Future studies should examine cessation-related characteristics among exclusive e-cigarette users and dual product young adult users.

Author Contributions: Conceptualization, M.A.A. and M.E.R.; methodology, M.A.A. and M.E.R.; formal analysis, M.A.A.; data curation, M.E.R.; writing—original draft preparation, M.A.A.; writingreview and editing, M.A.A., J.M.S. and M.E.R.; supervision, M.E.R.; project administration, M.E.R.; funding acquisition, M.E.R. All authors have read and agreed to the published version of the manuscript.

Funding: This research was supported by NCI grant number P50CA180908 and by a Pelotonia Research Award from The Ohio State University's Comprehensive Cancer Center.

Institutional Review Board Statement: The study was conducted according to the guidelines of the Declaration of Helsinki, and approved by the Institutional Review Board (or Ethics Committee) of The Ohio State University (protocol number 2016C0067, and date of approval 2 August 2016).

Informed Consent Statement: Informed consent was obtained from all subjects involved in the study.

Data Availability Statement: The data presented in this study are available upon reasonable request from the senior author (M.E.R.). Per our IRB protocol, the data are not publicly available due to ethical concerns regarding participant confidentiality.

Conflicts of Interest: The authors declare no conflict of interest.

\section{References}

1. Wang, T.W.; Neff, L.J.; Park-Lee, E.; Ren, C.; Cullen, K.A.; King, B.A. E-Cigarette Use Among Middle and High School Students —United States, 2020. MMWR Morb. Mortal. Wkly. Rep. 2020, 69, 1310-1312. [CrossRef] [PubMed]

2. Gentzke, A.S. Vital Signs: Tobacco Product Use Among Middle and High School Students—United States, 2011-2018. MMWR Morb. Mortal. Wkly. Rep. 2019, 68, 157-164. [CrossRef] [PubMed]

3. Bao, W.; Liu, B.; Du, Y.; Snetselaar, L.G.; Wallace, R.B. Electronic Cigarette Use Among Young, Middle-Aged, and Older Adults in the United States in 2017 and 2018. JAMA Intern. Med. 2020, 180, 313. [CrossRef] [PubMed]

4. Sidani, J.E.; Colditz, J.B.; Barrett, E.L.; Shensa, A.; Chu, K.-H.; James, A.E.; Primack, B.A. I Wake up and Hit the JUUL: Analyzing Twitter for JUUL Nicotine Effects and Dependence. Drug Alcohol Depend. 2019, 204, 107500. [CrossRef] [PubMed]

5. Vallone, D.M.; Cuccia, A.F.; Briggs, J.; Xiao, H.; Schillo, B.A.; Hair, E.C. Electronic Cigarette and JUUL Use Among Adolescents and Young Adults. JAMA Pediatr. 2020, 174, 277-286. [CrossRef] [PubMed]

6. Allem, J.-P.; Dharmapuri, L.; Unger, J.B.; Cruz, T.B. Characterizing JUUL-Related Posts on Twitter. Drug Alcohol Depend. 2018, 190, 1-5. [CrossRef]

7. Kavuluru, R.; Han, S.; Hahn, E.J. On the Popularity of the USB Flash Drive-Shaped Electronic Cigarette Juul. Tob. Control 2018, 28, 110-112. [CrossRef]

8. Huang, J.; Duan, Z.; Kwok, J.; Binns, S.; Vera, L.E.; Kim, Y.; Szczypka, G.; Emery, S.L. Vaping versus JUULing: How the Extraordinary Growth and Marketing of JUUL Transformed the US Retail e-Cigarette Market. Tob. Control 2019, $28,146-151$. [CrossRef]

9. Leventhal, A.M.; Madden, D.R.; Peraza, N.; Schiff, S.J.; Lebovitz, L.; Whitted, L.; Barrington-Trimis, J.; Mason, T.B.; Anderson, M.K.; Tackett, A.P. Effect of Exposure to E-Cigarettes with Salt vs Free-Base Nicotine on the Appeal and Sensory Experience of Vaping. JAMA Netw. Open 2021, 4, e2032757. [CrossRef]

10. Hoffman, J. The Price of Cool: A Teenager, a Juul and Nicotine Addiction. Available online: https://www.ncbi.nlm.nih.gov/ search/research-news/2356/ (accessed on 13 January 2021).

11. Case, K.R.; Hinds, J.T.; Creamer, M.R.; Loukas, A.; Perry, C.L. Who Is JUULing and Why? An Examination of Young Adult Electronic Nicotine Delivery Systems Users. J. Adolesc. Health 2020, 66, 48-55. [CrossRef] [PubMed]

12. Kong, G.; Bold, K.W.; Cavallo, D.A.; Davis, D.R.; Jackson, A.; Krishnan-Sarin, S. Informing the Development of Adolescent E-Cigarette Cessation Interventions: A Qualitative Study. Addict. Behav. 2021, 114, 106720. [CrossRef] [PubMed]

13. Pulvers, K.; Correa, J.B.; Krebs, P.; El Shahawy, O.; Marez, C.; Doran, N.; Myers, M. JUUL E-Cigarette Quit Attempts and Cessation Perceptions in College Student JUUL E-Cigarette Users. Am. J. Health Promot. 2020, 35, 624-632. [CrossRef] [PubMed]

14. Peraza, N.; Mayorga, N.A.; Garey, L.; Nizio, P.; Smit, T.; Zvolensky, M.J. Exploring Positive Expectancies and Quit Status among Adult Electronic Cigarette Users. Cogn. Behav. Ther. 2020, 49, 486-500. [CrossRef] [PubMed]

15. Garey, L.; Scott-Sheldon, L.A.J.; Olofsson, H.; Nelson, K.M.; Japuntich, S.J. Electronic Cigarette Cessation among Adolescents and Young Adults. Subst. Use Misuse 2021, 56, 1900-1903. [CrossRef]

16. Dyson, J.; Bhatnagar, M.; Skinner, J.; Crooks, M. Helping the Quitters Quit: A Systematic Review and Narrative Synthesis of the Barriers and Facilitators to e-Cigarette Cessation and the Support That Is Needed. Patient Educ. Couns. 2021. [CrossRef] 
17. Harrell, Z.A.T.; Huang, J.L.; Kepler, D.M. Brief Report: Affluence and College Alcohol Problems: The Relevance of Parent- and Child-Reported Indicators of Socioeconomic Status. J. Adolesc. 2013, 36, 893-897. [CrossRef]

18. Hosmer, D.W.; Lemeshow, S.; Sturdivant, R.X. Applied Logistic Regression, 3rd ed.; Wiley: Hoboken, NJ, USA, 2013; ISBN 978-0-470-58247-3.

19. Bursac, Z.; Gauss, C.H.; Williams, D.K.; Hosmer, D.W. Purposeful Selection of Variables in Logistic Regression. Source Code Biol. Med. 2008, 3, 17. [CrossRef]

20. Babyak, M.A. What You See May Not Be What You Get: A Brief, Nontechnical Introduction to Overfitting in Regression-Type Models. Psychosom. Med. 2004, 66, 411-421.

21. Zhu, S.-H.; Sun, J.; Billings, S.C.; Choi, W.S.; Malarcher, A. Predictors of Smoking Cessation in U.S. Adolescents. Am. J. Prev. Med. 1999, 16, 202-207. [CrossRef]

22. Hyland, A. Individual-Level Predictors of Cessation Behaviours among Participants in the International Tobacco Control (ITC) Four Country Survey. Tob. Control 2006, 15, iii83-iii94. [CrossRef] [PubMed]

23. Yong, H.-H.; Borland, R.; Balmford, J.; Hyland, A.; O'Connor, R.J.; Thompson, M.E.; Spittal, M.J. Heaviness of Smoking Predicts Smoking Relapse Only in the First Weeks of a Quit Attempt: Findings from the International Tobacco Control Four-Country Survey. Nicotine Tob. Res. 2014, 16, 423-429. [CrossRef] [PubMed]

24. Craigmile, P.F.; Onnen, N.; Schwartz, E.; Glasser, A.; Roberts, M.E. Evaluating How Licensing-Law Strategies Will Impact Disparities in Tobacco Retailer Density: A Simulation in Ohio. Tob. Control 2020, 30, e96-e103. [CrossRef] [PubMed]

25. Glasser, A.M.; Roberts, M.E. Retailer Density Reduction Approaches to Tobacco Control: A Review. Health Place 2021, 67, 102342. [CrossRef] [PubMed]

26. Pesko, M.F.; Courtemanche, C.J.; Catherine Maclean, J. The Effects of Traditional Cigarette and E-Cigarette Tax Rates on Adult Tobacco Product Use. J. Risk Uncertain. 2020, 60, 229-258. [CrossRef] 